\title{
Assessment of quality of prescription by dental students
}

\author{
Cariacy Silva de MOURA 1 , Janeth Oliveira Silva NAVES ${ }^{2}$, Eduardo Barbosa COELHO ${ }^{3}$, Erica Negrini LIA ${ }^{1}$
}

\author{
1- Dentistry Department, Faculty of Health Sciences, University of Brasília. \\ 2- Pharmacy Course, Faculty of Health Sciences, University of Brasilia. \\ 3- Department of Internal Medicine, Faculty of Medicine of Ribeirão Preto, University of São Paulo.
}

Corresponding address: Erica Negrini Lia - Dentistry Department - Faculty of Health Sciences - University of Brasilia - 70910-900 - Brasília - DF, Brazil Phone: +55 (61) 3107-1802 - e-mail: erica.lia@terra.com.br/ericalia@unb.br

Submitted: November 8, 2013 - Modification: January 14, 2014 - Accepted: January 14, 2014

\section{ABSTRACT}

O bjective: The main objective of this study was to evaluate changes in prescribing pattern of Dentistry students throughout academic course. Methods: A case of non-complicated dental extraction was presented to all students that had completed their pharmacology coursework (from 4th semester to the last semester). The students were grouped according to year of study and were asked to prescribe paracetamol for pain control. A maximal score of 5 points was calculated from three subscores for identification of professional and patient (1.0 point), drug concentration, dosage, and quantity (1.5 points); and drug information, instructions, and warnings ( 2.5 points). The data were expressed as medians [95\% confidence intervals (CIs)] and were compared using the Kruskal-Wallis test followed by Dunn's post hoc test. A $p<0.05$ value was considered statistically significant. A total of 92 students participated the study $\left(2^{\text {nd }}\right.$ year, $\mathrm{N}=12 ; 3^{\text {rd }}$ year, $\mathrm{N}=32 ; 4^{\text {th }}$ year, $\mathrm{N}=28 ; 5^{\text {th }}$ year, $N=20$ ). Results: The quality of prescription showed improvement between $2^{\text {nd }}$-year students $[2.0(1.5-2.5)]$ and $4^{\text {th }}$-year students $[3.2(2.9-3.5), p<0.05] ; 4^{\text {th }}$ - and $5^{\text {th }}$-year students [3.6 (3.5-3.8)] performed similarly. Lack of information about pharmacological treatment, side effects, and administration route were the major deficiencies observed. Conclusion: Although Dentistry students present a general improvement in their prescribing performance, deficiencies remain even in advanced students. The data suggest that the teaching of good prescription practices should extend throughout the later phases of preprofessional dental education.

Keywords: Teaching. Drug prescriptions. Dentistry.

\section{INTRODUCTION}

Prescribing medicine is integral to the clinical practice of Dentistry. Students working toward their Dentistry course learn how to prescribe medication during their studies, but, despite its importance, they generally do not learn about it in a systematized way. Traditionally, Brazilian dental students take basic pharmacology courses in their first few semesters that teach the pharmacokinetics and pharmacodynamics knowledge needed to understand pharmacotherapy. However, a true understanding of the context in which medications are prescribed comes in daily clinical practice and is not incorporated into basic pharmacology coursework. In general, students learn through observing their teachers and more experienced colleagues, acquiring practice in prescribing as they progress in their programs. They are introduced to fields requiring clinical observation from their fourth semester onwards. In Brazil, Dentistry courses are usually organized into 10 semesters taken over five years (although there are some courses organized according to year). Patients' individual characteristics (i.e., age, gender, and sociocultural profile) and medical histories (i.e., comorbidities and use of other medication) are often not considered. There are very few studies in the literature concerning prescription errors in Dentistry ${ }^{2,10}$, particularly by undergraduates $s^{3,4,5,9,11}$. Moreover, the lack of training in prescription and management of drug interactions has precipitated issues with identifying patients' problems and the therapeutic objective ${ }^{4}$. 
According to the World Health Organization (WHO)'s recommendations, prescriptions should identify the professional, the patient, and the mode of administration, as well as the medicine's pharmaceutical form, its dosage, frequency of use, duration of treatment together with patient guidance and information ${ }^{12}$. Extreme care should be taken to avoid errors in medical prescriptions as they may not only lead to difficulties and mistakes in dispensing medicines, but may also result in incorrect drug use that can make treatments ineffective or unsafe, which increases risks and healthcare costs ${ }^{1}$. Since the dental surgeon is a prescriber and needs to use medicines as part of his or her clinical dental practice, lack of adequate training for students is an important matter that impacts directly on the quality of medical prescriptions provided ${ }^{9}$.

Although there are data pointing to flaws in the training of prescribers, many teaching professionals, particularly those involved in clinical courses, have alleged that students do develop the ability to prescribe over the course of their education. Therefore, the objective of this study was to evaluate changes in the pattern of prescription over the Dentistry course study in a brazilian 5-year program.

\section{METHODS}

\section{Participants}

Students in their fourth to tenth semester of studying Dentistry at university Brasilia during the period from November 2010 to January 2011 who had completed their basic pharmacology coursework were enrolled in this study. The students were grouped according to their year in the program. All students volunteered after signing an informed consent form (Approval no. 112/2010, Institutional Ethics Committee).

\section{Evaluation}

We asked the students to self-evaluate their knowledge of clinical pharmacology as good, average, poor, or very poor. Then, we asked each participant to use an appropriate prescription form to prescribe paracetamol to control pain in a sample case of a dental extraction without complications. The participants had a maximum of 10 minutes to complete the prescription. We assigned a maximum score of 5 points to each prescription, where the score was the sum of subscores from three main areas: identification (1 point), pharmaceutical direction ( 2.5 points), and user information ( 1.5 points). The identification subscore ( 1 point) included correct identification of the prescriber ( 0.5 point) and the patient ( 0.5 point). The pharmaceutical direction subscore (1.5 point) included pharmaceutical form ( 0.5 point), concentration ( 0.5 point), and quantity to be purchased ( 0.5 point). And the user information subscore (2.5 points) included mode of administration (0.5), posology (0.5), length of treatment (0.5), warnings (0.5), date and span of prescription (0.5). We expressed the data as median values (95\% CI) and conducted comparisons using the Kruskal-Wallis test followed by the Dunn's post-test test. We adopted a significance value of $\mathrm{P}<0.05$.

\section{RESULTS}

In total, we evaluated 92 dental students, grouped according to their year in the program ( $2^{\text {nd }}$ year, $\mathrm{N}=12 ; 3^{\text {rd }}$ year, $\mathrm{N}=32 ; 4^{\text {th }}$ year, $\mathrm{N}=28 ; 5^{\text {th }}$ year, $\mathrm{N}=20$ ). The mean age of the study participants was 22 years old $( \pm 1.54)$. The cohort was $73 \%$ women and $27 \%$ men. In their self-evaluation of their knowledge of clinical pharmacology, the majority $(62 \%)$ of the students responded with "average". Only $10 \%$ described their knowledge as "good", whereas $26 \%$ and $2 \%$ described their knowledge

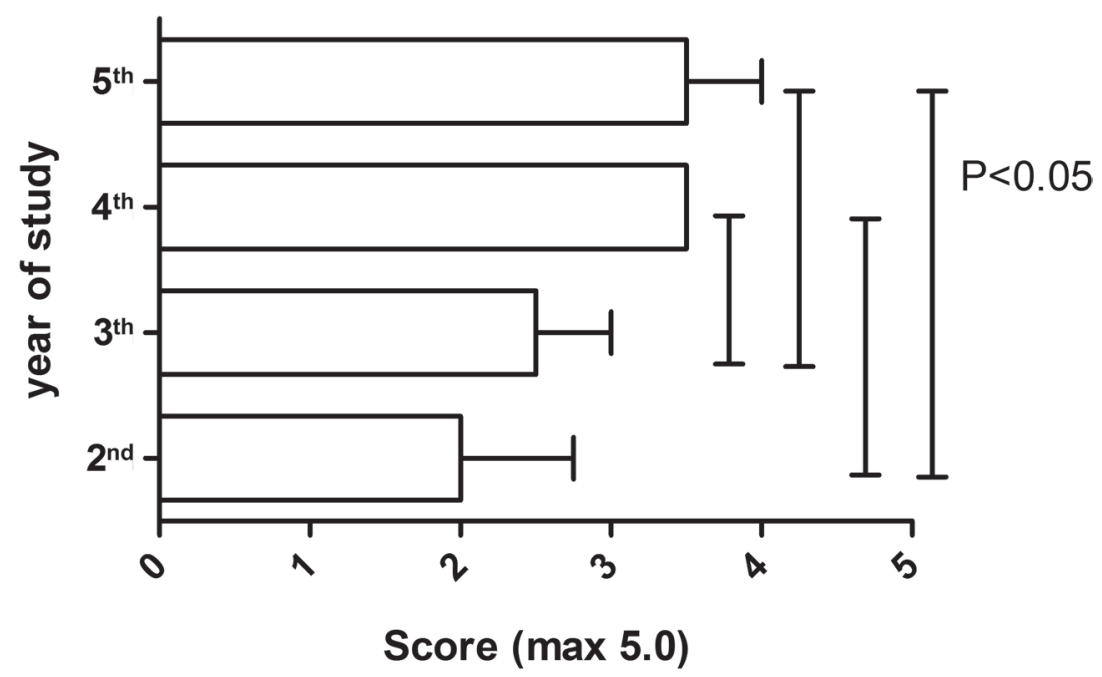

Figure 1- Total score achieved by Dentistry students for their paracetamol prescriptions 
as "poor" and "very poor", respectively.

Figure 1 summarizes how the quality of prescriptions varied by year in the program. As expected, there was an improvement in prescription quality in relation to students' time in the program $(p<0.0001)$. We observed a significant difference between scores achieved by $1^{\text {st }}$-year and $2^{\text {nd }}$-year students and scores achieved by students in their final two years. Second-year students had a median prescription quality total score of 2.0 points [(1.5-2.5), $p<0.005]$, whereas students in their final $\left(5^{\text {th }}\right)$ year of training had a median prescription quality total score of 3.5 points (3.4-3.8). However, this variation was not continuous, as there was no significant improvement between the $2^{\text {nd }}$ and $3^{\text {rd }}$ years, or between the $4^{\text {th }}$ and $5^{\text {th }}$ years.

In observing in detail the mistakes made by the students, we noted that failures to identify the patient or the prescriber were common. Although the $5^{\text {th }}$-year students generally performed better than their peers with fewer years in the patient/ prescriber identification subscore [0.6 (0.50-0.8)], that score differed significantly only versus $2^{\text {nd }}$-year students [0.3 (0.1-0.5); p<0.05] (Figure 2).

With respect to form of presentation, quantity, and dose/posology of the prescription, we observed that students in their final two years had scores similar to each other $\left[4^{\text {th }}\right.$ year $1.4(1.2-1.5) ; 5^{\text {th }}$ year $1.4(1.3-1.5)]$. Their scores were significantly higher than those achieved by students in their $2^{\text {nd }}$ [0.6 (0.4-0.9)] and $3^{\text {rd }}$ years $[0.7(0.5-0.9)]$, which did not differ from each other (Figure 3 ).

Students in their $5^{\text {th }}$ year of study generally performed better than the other students in use instructions, information, and patient warnings about using paracetamol. They scored significantly higher $[1.5(1.4-1.6)]$ than $2^{\text {nd }}$-year $[1.0(0.8-1.3)]$ and $3^{\text {rd }}$-year $[1.1(1.3-1.6)]$ students (Figure 4$)$.

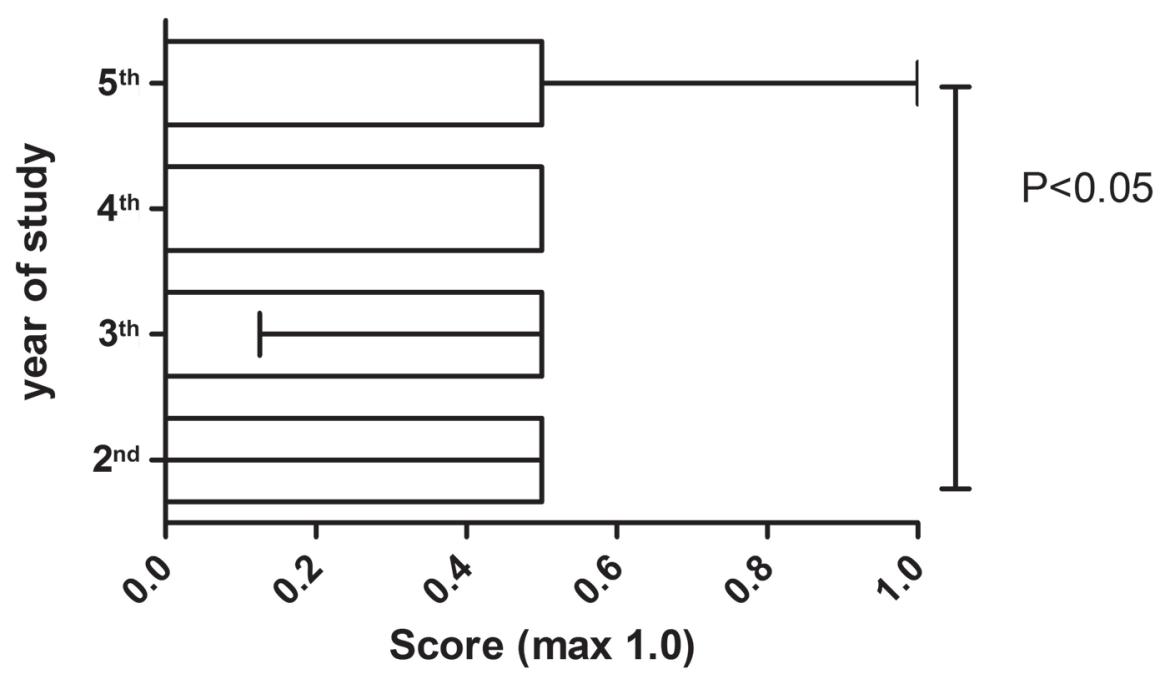

Figure 2- Partial score for patient and prescriber identification, obtained from the paracetamol prescriptions produced by Dentistry program students

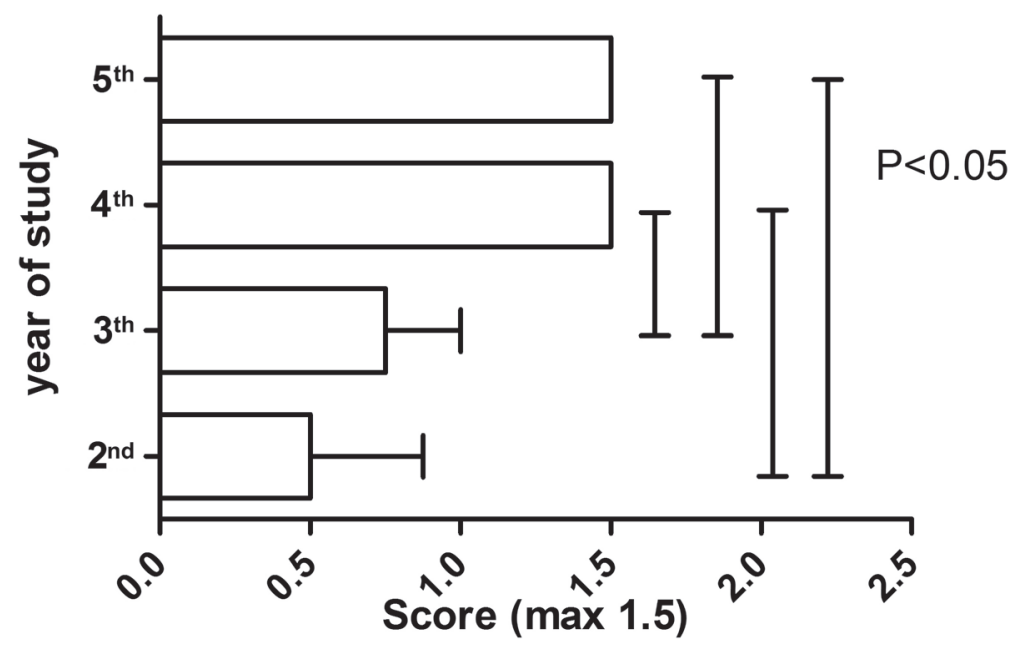

Figure 3- Partial score for information about the medicine (generic name, concentration, posology) on paracetamol prescriptions produced by Dentistry program students 


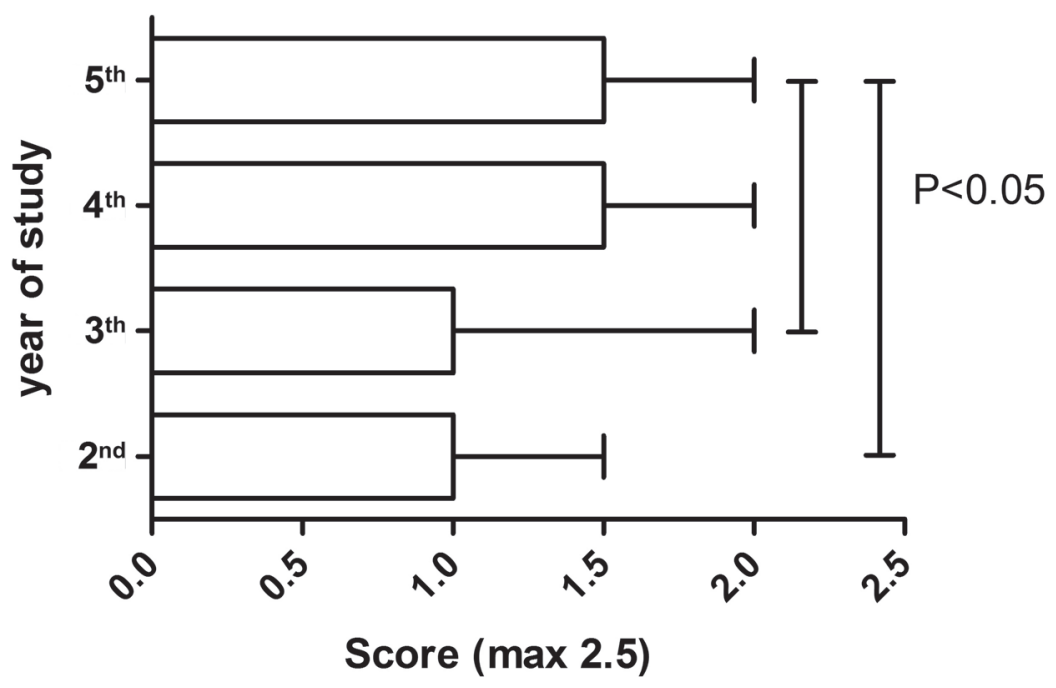

Figure 4- Partial score for warnings, use instructions, and side effects on paracetamol prescriptions produced by Dentistry program students

\section{DISCUSSION}

Good quality medical prescribing is one indicator of healthcare service quality. Inclusion of correct drug indications based on scientific evidence and an appropriately completed prescription are important parameters in the quality of pharmacotherapy delivery?

Our study showed that there was an aggregation of knowledge about drug prescribing over the Dentistry course program; however, important deficiencies were still present at the end of training. Clinical topics are introduced during the $2^{\text {nd }}$ and $3^{\text {rd }}$ years of the program, albeit with a low level of complexity. At this stage, students have the greatest difficulty with making prescriptions, which was most evident in terms of information about dosage/posology. This problem diminishes but does not disappear in the more advanced stages of the program, when students receive more practice at prescribing. Nevertheless, we observed that the acquisition of knowledge was not continuous in that there were no significant differences between the performance of $4^{\text {th }}$-year versus $5^{\text {th }}$-year students in the general quality of their prescriptions. The most common prescription flaws were failure to identify the patient, lack of information about the mode of administration or possible side effects, and absence of non-pharmacological directions.

A study conducted by Rauniar, et al. ${ }^{11}$ (2008) evaluated the prescribing abilities of $2581^{\text {st- }}$ and $2^{\text {nd }}$-year students in Medicine and Dentistry following a three-hour interactive session in clinical pharmacology using the objective structured practical examination. They evaluated two main components, the first of which concerned the prescriber (identification of the prescriber and patient, diagnosis, and signature) and the second of which concerned the drug (correct selection, dosage/posology, and quantity). In terms of prescriber data, $2^{\text {nd }}$-year students in both programs made more mistakes than $1^{\text {st-year students in either }}$ program. However, in terms of the information provided about the drugs, $2^{\text {nd }}$-year students in Medicine had a higher level of accuracy than $1^{\text {st }}$ year students, while the opposite pattern emerged for the Dentistry students. They reported that students acquired limited prescribing abilities in the pre-clinical stages of their programs. The students examined by Rauniar, et al. ${ }^{11}$ (2008) made errors that resembled those in our study. Our results provide a clear demonstration that students acquire knowledge up to a certain point (apparent plateau at $4^{\text {th }}$ year) and that they finish their training with important deficiencies that may influence their future actions in professional practice ${ }^{11}$.

A prior analysis of prescriptions, conducted by dental surgeons working in public health units in Brazil, showed that prescriptions commonly contained abbreviations and/or illegible letters and often lacked information about mode of administration, the total quantity of the drug being prescribed, dosage/posology, duration, and/or guidance about the proposed treatment ${ }^{10}$. Professionals who have completed their degrees should not make these mistakes, and it is very likely that the propensity for such mistakes may be traced back to gaps in their pre-doctoral preparation.

Although a study conducted with medical students showed low levels of perception about the importance of this question and a lack of awareness of the mistakes made ${ }^{8}$, the students in our study appeared aware of their difficulties. Curiously, while most of the students evaluated their knowledge of clinical pharmacology as "average" $(62 \%)$, a considerable number evaluated their knowledge as "poor" (26\%). Lack of knowledge on the name of the drug, its posology, and duration of treatment, 
doubts about how to fill out the prescription form, and uncertainty about the correct indication and possible allergies were the main difficulties indicated by students who were in their final year of the Dentistry program at a Mexican university ${ }^{4}$. Still, the students themselves are capable of recognizing that they had difficulties and doubts that made them feel insecure about prescribing.

Education about prescribing is lacking from undergraduate and graduate programs. Researchers have discussed the issue of the lack of integration of clinical knowledge into the basic knowledge curriculum $^{1}$, as well as the issues of insufficient time being devoted to teaching clinical pharmacology, and the lack of specific clinical training ${ }^{6}$. Based on our study's results, we suggest that there should be more emphasis on teaching good prescribing practices to Dentistry program students on a progressive and continual basis from the early semesters, when students have their first contact with clinical fields, through the final semester. To improve student involvement and motivation, teaching strategies should include internet tools in instructional units about prescribing based on scientific evidence as well as discussion of clinical cases and problem-based learning.

\section{CONCLUSIONS}

Although Dentistry students show a general improvement in their prescribing performance, deficiencies remain even in advanced students, particularly in relation to uses of the drug being prescribed. The data suggest that teaching of good prescription practices should extend throughout the later phases of pre-professional dental education.

\section{REFERENCES}

1- Aronson JK. A prescription for better prescribing. $\mathrm{Br}$ J Clin Pharmacol. 2006;61(5):487-91.

2- Castilho LS, Paixão HH, Perini E. Prescrição de medicamentos de usos sistêmico por cirurgiões-dentistas, clínicos gerais. Rev Saude Publica. 1999;33(3):287-94.

3- Garbin CAS, Garbin AJI, Rovida TAS, Moroso TT, Dossi AP. Conhecimento sobre prescrição medicamentosa entre alunos de odontologia: o que sabem os futuros profissionais? Rev Odontol UNESP. 2007;36(4):323-9.

4- Gómez-Oliván LM, Márquez Rodríguez $S$, Pontigo Loyola P, Téllez López A, Amaya-Chávez A, Galar-Martínez M. The prescription of drugs in a dental clinic of a Mexican university hospital. Farm Hosp. 2007;31(3):169-72.

5- Guzmán-Álvarez R, Medeiros M, Reyes Lagunes LI, CamposSepúlveda $A E$. Knowledge of drug prescription in dentistry students. Drug Healthc Patient Saf. 2012;4:55-9.

6- Gwee MCE. Teaching of medical pharmacology: the need to nurture the early development of desired attitudes for safe and rational drug prescribing. Med Teach. 2009;31(9):847-54.

7- Hassan NB, Ismail HC, Naing L, Conroy RM, Rahman ARA. Development and validation of a new Prescription Quality Index. $\mathrm{Br}$ J Clin Pharmacol. 2010;70(4):500-13.

8- Lempp H, Seabrook M, Cochrane M, Rees J. The transition from medical student to doctor: perceptions of final year students and preregistration house officers related to expected learning outcomes. Int J Clin Pract. 2005;59(3):324-9.

9- Lúcio PSC, Castro RD, Barreto RC. Prescrição medicamentosa sob a visão de estudantes em Odontologia. Arq Odontol. 2011;47(4):189-95.

10- Mendonça JMD, Lyra DP Jr, Rabelo J, Siqueira J, Balisa-Rocha B, Gimenes FRE, et al. Analysis and detection of dental prescribing errors at Primary Health Care Units in Brazil. Pharm World Sci. 2010;32(1):30-5.

11- Rauniar GP, Roy RK, Das BP, Bhandari G, Bhattacharya SK. Prescription writing skills of pre-clinical medical and dental undergraduate students. Nepal Med Assoc. 2008;47(172):197200.

12- World Health Organization. Guide to good prescribing: a practical manual. Geneva: WHO; 1994.

\section{DECLARATION OF INTEREST}

The authors report no conflicts of interests. 